\title{
Randomised controlled trial of low dose fentanyl infusion in preterm infants with hyaline membrane disease
}

\author{
P Lago, F Benini, C Agosto, F Zacchello
}

\begin{abstract}
Aim-To evaluate the effects of low dose fentanyl infusion analgesia on behavioural and neuroendocrine stress response and short term outcome in premature infants ventilated for hyaline membrane disease. Methods-Twenty seven ventilated preterm infants were randomly assigned to receive a mean fentanyl infusion of 1.1 (0.08 SE) $\mu \mathrm{g} / \mathrm{kg} / \mathrm{h}$ for 75 (5) hours, and 28 untreated infants were considered a control group. A behavioural sedation score was used to assess the infants' behaviour. Urinary metanephrine and the normetanephrine:creatinine molar ratio were determined at $0,24,48$ and 72 hours. Outcome data and ventilatory indexes were recorded for each infant.
\end{abstract}

Results-The fentanyl group showed significantly lower behavioural stress scores and $\mathrm{O}_{2}$ desaturations than controls and lower urinary concentrations of metanephrine and normetanephrine at 24, 48, 72 hours. The two groups showed no significant difference in ventilatory variables or short term outcome.

Conclusions-A short course of low dose fentanyl infusion reduces behavioural sedation scores, $\mathrm{O}_{2}$ desaturations and neuroendocrine stress response in preterm ventilated infants.

(Arch Dis Child Fetal Neonatal Ed 1998;79:F194-F197)

Keywords: fentanyl; hyaline membrane disease; stress response; behavioural ventilation

Premature infants requiring intensive care undergo many uncomfortable and invasive procedures during their hospital stay. Even in premature infants, painful stimuli are coupled with changes in physiological (heart rate, respiratory rate, blood pressure, intracranial pressure, oxygen saturation), behavioural, and hormonal parameters (increased steroids, catecholamines and glucagon). ${ }^{1}$ Metabolic (hypermetabolic and catabolic states) and immune functions (depressed immune responsiveness) are also affected..$^{23} \mathrm{~A}$ reduced pain threshold after repeated stimulation or local tissue injury has also been widely reported. ${ }^{4}$ During this hypersensitivity period, all sensorial stimulation-such as that produced by handling, physical examination, light and noise-will be perceived as noxious stimuli, producing stress. ${ }^{56}$ In neonatal intensive care units clinically significant physiological and haemodynamic responses have been described in response to endotracheal suctioning, nursing procedures, and mechanical ventilation. ${ }^{7-11}$ These metabolic and neuroendocrine modifications over prolonged periods may increase the number of complications during the course of hyaline membrane disease and might cause persistent catabolism and impaired growth and organ maturation. ${ }^{5}$ Administration of exogenous opioid analgesia to stressed individuals could blunt the physiological, hormonal, and metabolic response to stress, decrease plasma $\beta$-endorphin concentrations, and improve clinical outcome. ${ }^{12}{ }^{13}$ This suggests that a reduction in stress could be beneficial. In older children and adults an endotracheal tube is generally considered uncomfortable, so analgesia and sedation are routinely administered. ${ }^{13}$ Whether similar criteria should apply to neonates is still hotly debated. Previous studies have shown that opioid infusion during mechanical ventilation in premature babies might reduce the behavioural and hormonal stress response (plasma adrenaline, cortisol and 11-deoxycortisol concentrations). ${ }^{14-16}$ However, preterm infants treated with fentanyl analgesia seem to need greater ventilatory support during the early phase of respiratory distress syndrome. ${ }^{15}$

Our investigation aimed to assess the effect of low dose fentanyl infusion on behavioural sedation scores, neuroendocrine markers of stress, and short term clinical outcome in premature infants mechanically ventilated for hyaline membrane disease.

\section{Methods}

All premature infants (gestational age 26 to 34 weeks) requiring intermittent mandatory ventilation with a mean airway pressure greater than $7.0 \mathrm{~cm} \mathrm{H}_{2} \mathrm{O}$ and the presence of indwelling catheters for hyaline membrane disease between April 1996 and May 1997 were included in this trial. Local ethics committee and informed parental consent were obtained. The infants were randomly assigned to receive fentanyl by continuous infusion or nothing within the first 24 hours of life. The nurse, who completed the behavioural sedation score, and the laboratory technician, who analysed the metanephrine concentration, were blinded to the randomisation. Exclusion criteria for fentanyl administration included: asphyxia (Apgar score of less than 5 at 5 minutes), fetal drug exposure (shown by positive results of urine screening in either the mother or the baby, or a history of prenatal drug abuse), sepsis and major congenital anomalies. No other analgesics, seda- 
Table 1 Behavioural sedation score

\begin{tabular}{|c|c|c|c|c|}
\hline & 0 & 1 & 2 & 3 \\
\hline $\begin{array}{l}\text { Behavioural } \\
\text { status }\end{array}$ & Sleep & Quiet awake, alert, not active & $\begin{array}{l}\text { Active awake, alert, movement of } \\
\text { extremities }\end{array}$ & Vigorous activity, kicking, crying \\
\hline Muscular tone & Generalised hypotonia & Reduced muscular tone & Normal muscular tone & Increased muscular tone \\
\hline Motor response & No reaction & Spontaneous movements with pain & Spontaneous global movements & $\begin{array}{l}\text { Continuos spontaneous movements } \\
\text { restless }\end{array}$ \\
\hline Mimic & No reaction & Grimacing only with pain & $\begin{array}{l}\text { Cries only when with pain, rapid } \\
\text { return to rest }\end{array}$ & Cries, difficult to soothe \\
\hline Breathing & $\begin{array}{l}\text { No spontaneous } \\
\text { respiration }\end{array}$ & $\begin{array}{l}\text { Spontaneous breathing, fully } \\
\text { synchronised }\end{array}$ & $\begin{array}{l}\text { Spontaneous breathing, not } \\
\text { synchronous }\end{array}$ & $\begin{array}{l}\text { Tachypnoea, fighting with the } \\
\text { ventilator }\end{array}$ \\
\hline Aspiration & $\begin{array}{l}\text { No reaction when } \\
\text { aspired }\end{array}$ & $\begin{array}{l}\text { Grimacing only, no movements of } \\
\text { extremities and/or } \mathrm{O}_{2} \text { desaturation } \\
<90 \%\end{array}$ & $\begin{array}{l}\text { Cries, little coughing, but soon } \\
\text { returns to rest and/or } \mathrm{O}_{2} \text { desaturation } \\
<80 \%\end{array}$ & $\begin{array}{l}\text { Strong opposition, intense coughing, } \\
\text { cries difficult to soothe; and/or } \mathrm{O}_{2} \\
\text { desaturation }<70 \%\end{array}$ \\
\hline
\end{tabular}

tives, or muscle relaxants were permitted for the duration of the study. All neonates admitted to the study were evaluated using the CRIB score to measure the differences in risk of hospital death as a result of initial disease severity. The CRIB score takes into account birthweight, gestational age, presence of congenital malformation, maximum base excess, minimum and maximum appropriate inspired oxygen concentrations in the first 12 hours of life. ${ }^{17}$ Fentanyl infusion was given at $0.5-2$ $\mu \mathrm{g} / \mathrm{kg} / \mathrm{h}$ and adjusted to render the neonate sedated but arousable according to the sedation score adapted by Hartwig ${ }^{18}$ (table 1). Scores were assigned every two hours.

Single values and the sum of the sedation score criteria reflected the cumulative stress and pain levels. A low score indicates a more heavily sedated infant: reliable sedation was indicated by sleep or quiet awake status, normal muscular tone, minimal movement of discomfort and $\mathrm{O}_{2}$ desaturation in response to routine patient care, including tracheal suctioning, synchronous and regular respiration. Total fentanyl dose received during the entire treatment period, the peak infusion rate, defined as the highest infusion rate, the mean fentanyl rate, the length of infusion and duration of ventilation, were recorded. As soon as the neonate recovered from the pulmonary disease, the fentanyl infusion rate was decreased by $30 \%$ every 8 hours, starting 24 hours before extubation, permit suspension of mechanical ventilation and to facilitate enteral feeding.

Baseline urine samples and those taken at 24,48 , and 72 hours after fentanyl administration were collected and urinary metanephrinenormetanephrine:creatinine molar ratio concentrations were measured as stress response markers. The urine samples were added to concentrated $\mathrm{HCl}$ to reduce the $\mathrm{pH}$ to $1-2$. The samples were analysed for metanephrine and normetanephrine by high performance liquid chromatography using a Beckman analyser. Urinary creatinine excretion values were determined using the Beckman CX-7 automatic analyser with the Jaffe colorimetric method, as described elsewhere. ${ }^{19-21}$

With respect to ventilator management arterial carbon dioxide tensions between $45 \mathrm{~mm}$ $\mathrm{Hg}$ and $55 \mathrm{~mm} \mathrm{Hg}$ and oxygen tensions between 50 and $80 \mathrm{~mm} \mathrm{Hg}$ were maintained. The peak inspiratory pressure and fraction of inspired oxygen were decreased first, then the respiratory rate. Gestational age, birthweight, sex, Apgar scores, location of birth, method of delivery, use of antenatal steroids and CRIB score were recorded for each patient. Short term outcome was assessed for the radiographic severity of hyaline membrane disease, based on Edwards' grading method, which takes into account granularity of the lung, air bronchograms, cardiac and diaphragmatic silhouettes and aeration up to grade $5 .^{22}$ The need for surfactant replacement, evidence of clinically significant patent ductus arteriosus, incidence of air leak (pulmonary emphysema and pneumothorax), bronchopulmonary dysplasia (defined as a requirement for supplemental oxygen at 28 days of life), intraventricular haemorrhage, periventricular leucomalacia, days of ventilatory support and oxygen treatment, days of exclusive enteral feeding, growth (days to reach birthweight) and hospital stay were also assessed.

Statistical analysis was performed using analysis of variance for continuous data such as ventilatory indexes, physiological markers of stress, and sedation score. The two tailed Student's $t$ test was applied for independent variables such as birthweight and gestational age. A $\chi^{2}$ analysis and Fisher's Exact Test were performed for categorical data such as method of delivery, sex, and short term clinical outcome. A p value of $<0.05$ was regarded as significant.

\section{Results}

Fifty five infants were enrolled in the study: 27 received fentanyl infusion. Two patients died: one (in the fentanyl group) of progressive intraventricular haemorrhage at the age of 15 days and the other (in the control group) of intractable respiratory distress syndrome at the age of eight days. Both were excluded from the statistical analysis. The two groups were

Table 2 Characteristics of study population

\begin{tabular}{llll}
\hline & $\begin{array}{l}\text { Fentanyl } \\
\text { group }\end{array}$ & $\begin{array}{l}\text { Control } \\
\text { group }\end{array}$ & p Value \\
\hline $\begin{array}{l}\text { Number } \\
\text { Gestational age }\end{array}$ & 26 & 27 & \\
$\quad$ (weeks) & $31(2)$ & $31(2)$ & \\
$\begin{array}{l}\text { Birthweight (g) } \\
\text { Sex M:F }\end{array}$ & $1513(491)$ & $1609(484)$ & \\
Inborn:outborn & $15 / 11$ & $16 / 11$ & \\
Caesarean section & $20 / 6$ & $22 / 5$ & NS \\
Apgar score & 24 & 20 & \\
$\quad 1$ min & $6(2)$ & $5(2)$ & \\
$\quad 5$ min & $8(2)$ & $7(2)$ & \\
Crib score & $3(2)$ & $2(2)$ & \\
Antenatal steroids & $14(54 \%)$ & $12(44 \%)$ & \\
\hline
\end{tabular}


Table 3 Behavioural sedation scores, urinary metanephrine, normetanephrine:creatinine ratio in fentanyl and control groups

\begin{tabular}{lllll}
\hline & Basal & At 24 hours & At 48 hours & At 72 hours \\
\hline Sedation score & & & & \\
$\quad$ Fentanyl group & $10(2)$ & $7(1)$ & $7(1)$ & $7(2)$ \\
$\quad \begin{array}{l}\text { Control group } \\
\text { p value }\end{array}$ & $10(2)$ & $10(2)$ & $11(2)$ & $10(2)$ \\
Metanephrine $(\mu \mathrm{mol} / \mathrm{mol}$ creatinine) & $\mathrm{NS}$ & $<0.05$ & $<0.05$ & $<0.05$ \\
$\quad$ & & & & \\
$\quad$ Fentanyl group & $0.40(0.21)$ & $0.30(0.18)$ & $0.26(0.13)$ & $0.20(0.12)$ \\
$\quad$ Control group & $0.36(0.19)$ & $0.57(0.26)$ & $0.89(0.46)$ & $0.91(0.44)$ \\
p value & $\mathrm{NS}$ & $<0.05$ & $<0.05$ & $<0.05$ \\
Normetanephrine $(\mu \mathrm{mol} / \mathrm{mol}$ creatinine) & $1.59(1.19)$ & $1.20(0.40)$ & $1.13(0.54)$ & $1.27(0.62)$ \\
$\quad$ Fentanyl group & $1.73(0.91)$ & $1.96(0.81)$ & $2.15(0.42)$ & $2.43(0.72)$ \\
$\quad$ Control group & $\mathrm{NS}$ & $\mathrm{NS}$ & $<0.05$ & $<0.05$ \\
$\quad$ p value & & &
\end{tabular}

Table 4 Ventilatory indexes in fentanyl and control groups

\begin{tabular}{lllll}
\hline & Basal & At 24 hours & At 48 hours & At 72 hours \\
\hline FIO $_{2}$ & $52(20)$ & $42(22)$ & $38(12)$ & $29(10)$ \\
$\quad$ Fentanyl group & $44(21)$ & $35(12)$ & $36(15)$ & $26(6)$ \\
$\quad \begin{array}{l}\text { Control group } \\
\text { p value }\end{array}$ & $\mathrm{NS}$ & $\mathrm{NS}$ & $\mathrm{NS}$ & $\mathrm{NS}$ \\
PIP & $23(4)$ & $21(4)$ & $21(3)$ & $19(2)$ \\
$\quad$ Fentanyl group & $21(3)$ & $19(3)$ & $20(1)$ & $19(2)$ \\
$\quad$ Control group & $\mathrm{NS}$ & $\mathrm{NS}$ & $\mathrm{NS}$ & $\mathrm{NS}$ \\
p value & $37(9)$ & $30(11)$ & $34(14)$ & $31(10)$ \\
IMV rate & $35(1)$ & $27(10)$ & $27(9)$ & $26(25)$ \\
$\quad$ Fentanyl group & $\mathrm{NS}$ & $\mathrm{NS}$ & $\mathrm{NS}$ & $\mathrm{NS}$ \\
$\begin{array}{l}\text { Control group } \\
\text { p value }\end{array}$ & & & \\
\hline
\end{tabular}

$\mathrm{FIO}_{2}$, fraction of inspired oxygen; PIP, peak inspiratory pressure; IMV, intermittent mandatory ventilation.

homogeneous for sex, birthweight, gestational age, antenatal steroids, method of delivery, Apgar scores and CRIB score (table 2).

The fentanyl group received continuous intravenous infusions of $1.1(0.08 \mathrm{SE}) \mu \mathrm{g} / \mathrm{kg} / \mathrm{h}$, with a peak infusion rate of $1.5(0.09) \mu \mathrm{g} / \mathrm{kg} / \mathrm{h}$, for a total dose of $84(8) \mu \mathrm{g} / \mathrm{kg}$. The mean infusion time was 75 (5) hours. The weaning of $30 \%$ infusion rate every eight hours, starting 24 hours before the expected extubation, was well tolerated. No withdrawal symptoms or other clinically significant side effects (bradycardia, hypotension or apnoea episodes) were observed during infusion.

Behavioural sedation scores were significantly lower in the group receiving fentanyl at 24,48 , and 72 hours. Urinary concentrations of metanephrine and normetanephrine at 24, 48 , and 72 hours were significantly lower in the fentanyl group. Baseline concentrations were not significantly different between the two groups (table 3 ). There were no differences in ventilatory parameters, carbon dioxide tension, or oxygen tension between the two groups during the study, although the fentanyl group seems to have had a higher grade of hyaline at study entry and required more doses of surfactant (tables 4,5 ). The average time spent on the ventilator was 9 days ( $95 \%$ CI 5-12)in the fentanyl group and 7 days (95\% CI 3-11) in the control group. The duration of $\mathrm{O}_{2}$ dependence (fentanyl group: 17 days (95\% CI 7-27); control group 12 days (95\% CI 5-19)) was not significantly different. Similarly, no significant differences were detectable between the two groups in the incidence of air leak (pneumothorax and pulmonary interstitial emphysema), bronchopulmonary dysplasia, intraventricular haemorrhage, periventricular leucomalacia, necrotising enterocolitis, feed tolerance, growth and hospital stay (fentanyl group: 40 days (95\% CI 31-49); control group: 38 days (95\% CI 29-47)) (table 5).

\section{Discussion}

The beneficial effects of pain and stress control in neonates has been shown by the temporary reduction in repeated hypoxic episodes, improved haemodynamic stability, ${ }^{8-11}$ and attenuation of neuroendocrine response to stress. ${ }^{12-16}$ During physiological stress, the release of numerous hormones, cytokines, humoral factors, and specific outflows from the central nervous system cause a cascade of reactions leading to pathological complications and persistent catabolism, with the inhibition of protein synthesis required for optimal growth and organ maturation. Furthermore, in premature neonates the pain threshold decreases following repeated sensorial stimuli, and even non-noxious stimuli may be perceived as stressful. ${ }^{6}$ The effects of these uncontrolled behavioural and neuroendocrine responses provide a physiological rationale for considering analgesia and sedation in the routine clinical management of premature infants. A few reports have described the use of opioids in mechanically ventilated preterm infants. There is evidence of a significant reduction in catecholamine concentrations in premature mechanically ventilated babies treated randomly with morphine, without significant side effects. ${ }^{14}{ }^{15}$ However, Orsini et al suggested that although fentanyl can reduce physiological indicators of pain and stress, increased ventilatory support was required compared with infants receiving placebo. ${ }^{16}$ The possible effects of an increased need for ventilator support during fentanyl infusion are typically present on the third day of infusion and may be due to depression of respiratory drive, although this seems to be transient and does not interfere with the weaning from the ventilator. ${ }^{15}$ To date, no data are available on the effects of opioid sedation on preterm pulmonary functions, while the data are controversial in older children. $^{23} 24$

In our study, administration of fentanyl infusion in preterm infants ventilated for hyaline membrane disease significantly reduced behavioural sedation scores, $\mathrm{O}_{2}$ desaturation, and neuroendocrine stress response. Neuro-

Table 5 Short and long term outcome of study population

\begin{tabular}{llll}
\hline & $\begin{array}{l}\text { Fentanyl } \\
\text { group } \\
(n=26)\end{array}$ & $\begin{array}{l}\text { Control } \\
\text { group } \\
(n=27)\end{array}$ & p Value \\
\hline HMD grading & $15(5)$ & $12(5)$ & $<0.05$ \\
Surfactant doses & $2(1)$ & $1(1)$ & $<0.05$ \\
Days on ventilator & $9(8)$ & $7(10)$ & \\
Days of $\mathrm{O}_{2}$ & $17(23)$ & $11(17)$ & \\
$\quad$ dependence & 3 & 2 & $\mathrm{NS}$ \\
Air leak & $16(61 \%)$ & $11(41 \%)$ & \\
PDA & 6 & 2 & \\
BPD & 0 & 2 & \\
IVH grading III/IV & 3 & 1 & \\
PVL & 0 & $12(9)$ & \\
NEC & $12(4)$ & $35(5)$ & \\
Total enteral feeding & $12(7)$ & & \\
Growth to BW (days) & $12(2)$ & \\
Hospital stay (days & $39(22)$ & & \\
\end{tabular}

HMD, hyaline membrane disease; PDA, patent ductus arteriosus; BPD, bronchopulmonary dysplasia; IVH, intraventricular haemorrhage; PVL, periventricular leucomalacia; NEC, necrotising enterocolitis. 
endocrine markers of pain are useful in preterm babies. Anand found that infants treated with fentanyl anaesthesia for patent ductus arteriosus ligation showed a lower stress response than those who were not treated. ${ }^{3}$ Opioid infusions have already been shown to reduce plasma catecholamines concentrations, ${ }^{14}$ no data are available on urinary metanephrine and normetanephrine concentrations in relation to opioid infusion. Moreover, as urine output may be fairly erratic during the first days of life, we chose to measure the metanephrine:creatinine molar ratio. We found that urinary metanephrine and normetanephrine:creatinine ratios were lower during fentanyl infusion. This evidence confirms the previous data on the effects of opioids on catecholamines during mechanical ventilation.

Moreover, we could find no significant difference in ventilatory support during administration of fentanyl. This might be due to the decreased fentanyl doses and duration of continuous infusion with respect to the previous study ${ }^{16}$ and might mean that our regimen of fentanyl infusion at $0.5-2 \mu \mathrm{g} / \mathrm{kg} / \mathrm{h}$, based on behavioural sedation score and weaned 24 hours before the expected extubation, is safe and effective in reducing behavioural sedation scores, $\mathrm{O}_{2}$ desaturations, and neuroendocrine stress response in preterm ventilated infants, and has no significant effects on the duration of mechanical ventilation or enteral feeding tolerance. Our study showed no significant differences in short term outcomes, probably because a small population sample was analysed.

In conclusion, a short term infusion of $0.5-$ $2 \mu \mathrm{g} / \mathrm{kg} / \mathrm{h}$ fentanyl is a well tolerated sedative for premature infants undergoing mechanical ventilation for hyaline membrane disease. It reduces behavioural and neuroendocrine stress responses with no effects on duration of mechanical ventilation or enteral feeding tolerance. However, a larger randomised placebo controlled study would be needed to assess the advantages of routine infusion on long term outcome.

We thank the neonatal intensive care nurses of the Department of Pediatrics of the University of Padova for their help during of Pediatrics of the University of Padova for their help during
this study. Their continued support and devotion to the care of this study. Their continued support
our patients is greatly appreciated.

1 Anand KJS, Hickey PR. Pain and its effects in the human neonate and fetus. N Engl F Med 1987;317:1321-9.

2 Anand KJS, Hansen DD, Hickey PR. Hormonal-metabolic stress responses in neonates undergoing cardiac surgery. Anesthesiology 1990;73:661-70.
3 Anand KJS, Sippell WG, Aynsley Green A. Randomized trial of fentanyl anesthesia in preterm babies undergoing surgery: effects on the stress response. Lancet 1987;i:2438.

4 Fitzgerald M, Millard C, Macintosh N. Cutaneous hypersensitivity following peripheral tissue damage in newborn infants and its reversal with topical anaesthesia. Pain 1989;39:31-6.

5 Anand KJS. Relationships between stress responses and clinical outcome in newborns, infants, and children. Crit Care Med 1993;21:S356-9.

6 Fitzgerald M. Development of pain pathways and mechanisms. In: Anand KJS, McGrath PJ, eds. Pain in neonates. Amsterdam: Elsevier Science Publishers, 1993:19-37.

7 Ionides SP, Weiss MG, Angelopoulos M, Myers T, Handa RJ. Plasma beta-endorphin concentrations and analgesiamuscle relaxation in the newborn infants supported by mechanical ventilation. $\mathcal{F}$ Pediatr 1994;125:113-16.

8 Pokela ML. Pain relief can reduce hypoxemia in distressed neonates during routine treatment procedures. Pediatrics 1994;93:379-83.

9 Pokela ML, Koivisto M. Physiological changes, plasma Beta-endorphin and cortisol response to tracheal intubation in neonates. Acta Paediatr 1994;83:152-6.

10 Greisen GS, Frederiksen PS, Hertel J. Catecholamine response to chest physiotherapy and endotracheal suctioning in preterm infants. Acta Paediatr Scand 1985;74:525-9.

11 Perlman JM, Goodman S, Kreusser KL, Volpe JJ. Reduction in intraventricular hemorrhage by elimination of fluctuating cerebral blood-flow velocity in preterm infants with respiratory distress syndrome. $N$ Engl 7 Med 1985;312:1353-7.

12 Barker DP, Rutter N. Exposure to invasive procedures in neonatal intensive care admissions. Arch Dis Child 1995;72:F47-8

13 Bauchner H, May A, Coates E. Use of analgesic agents for invasive medical procedures in pediatric and neonatal intensive care units. $\mathcal{F}$ Pediatr 1992;121:647-9.

14 Quinn NW, Wild J, Dean HG, et al. Randomized double-blind controlled trial of effect of morphine on catecholamine concentrations in ventilated preterm babies. Lancet 1993:342:324-7.

15 Orsini AJ, Kathleen HL, Costarino A, Dettore MD, Stefano JL. Routine use of fentanyl infusion for pain and stress reduction in infants with respiratory distress syndrome. $\mathcal{f}$ Pediatr 1996;129:140-5.

16 Roth B, Schlunder C, Houben F, Gunther M, Theisohn M. Analgesia and sedation in neonatal intensive care using fentanyl by continuous infusion. Dev Pharmacol Ther 1991;17:121-7.

17 De Courcy-Wheeler RHB, Wolfe CDA, Fitzgerald A, Spencer M, Goodman JDS, Harold RG. Use of the CRIB (Clinical Risk Index for Babies) score in prediction of neonatal mortality and morbidity. Arch Dis Child 1995;73:F32-6.

18 Hartwig S, Roth B, Theisohn M. Clinical experience with continuous intravenous sedation using midazolam and fentanyl in the paediatric intensive care unit. Eur $\mathcal{F}$ Pediatr 1991;150:784-8.

19 Jouve J, Mariotte N, Sureau C, Muh JP.High-performance liquid chromatography with electrochemical detection for the simultaneous determination of the methoxylated amine normetanephrine, metanephrine and

Ekblad $\mathrm{H}$, Kero P, Korvenrata $\mathrm{H}$, Scheinin M. Sympathoadrenal activity in preterm infants during the first five days of life. Biol Neonate 1992;61:294-301.

21 Marxwell GM, Crompton S, Davies A. Urinary catecholamine levels in the newborn infant. Eur $f$ Pediatr 1985;143:171-4.

22 Edwards DK, Hilton SVW, Merrit TA, Hallman M, Mannino F, Boynton BR. Respiratory distress syndrome treated with human surfactant: radiographic finding. Radiology 1985;157: 329-34.

23 Iarazuzta J, Pascucci R, Perlman N, Wessel D. Effects of fentanyl administration on respiratory system compliance in infants. Crit Care Med 1993;21:1001-4

24 Marty J, Desmonts JM. Effects of fentanyl on respiratory pressure-volume relationship in supine anesthetized children. Acta Anaesth Scand 1981;25:293-6. 